\title{
Plan to Budget and Cash Management in Uasin Gishu County Government, Kenya
}

\author{
William Shisamba ${ }^{1 *} \quad$ Dr. Muganda Munir ${ }^{1} \quad$ Dr. Alala Ondiek ${ }^{2}$ \\ 1.School of Business, Economics and Finance, Kibabii University, PO box 1699-50200, Bungoma, Kenya \\ 2.School of Accounting and Finance, Masinde Muliro University of Science and Technology, PO box 190-50100 \\ Kakamega, Kenya
}

\begin{abstract}
Techniques and systems to improve and modernize cash management in the non-private sectors are increasingly being explored by governments in less developed countries. Efficient management of public funds mainly focuses on budgeting, procurement and reporting. The purpose of this study was to examine the effect of plan to budget module of Integrated Financial Management Information System and cash management in Uasin Gishu County Government. Government policy was the moderating variable. This was necessitated by the fact that the Kenyan government has experienced consistent misappropriation of public funds in county governments despite the introduction of Integrated Financial Management Information System as an appropriate modern accounting system for efficient public cash management. The study was based on systems theory. The target population of the study was 185 employees from sections using Integrated Financial Management Information System. A sample size of 177 respondents was drawn from the population by use of stratified random sampling method. A well-structured questionnaire was used to collect data. Construct validity of the research instruments was determined using KaiserMeyer-Olkin (KMO) and Bartlett's tests with values of above 0.5 and probability values less than 0.05 considered valid. Internal consistency was measured by Cronbach's alpha with alpha coefficient of above 0.70 being considered reliable. Both descriptive and inferential statistics was used to analyse the data. Multiple regression and Pearson correlation were used for inferential statistics. Data results and findings were displayed in tables, figures, graphs and pie chart. The study findings revealed that plan to budget module had statistically significant influence on Cash Management in Uasin Gishu County Government by explaining $12.9 \%$ of the variation in Cash Management [Adjusted R Square $=0.129, \mathrm{~F}(1,172)=26.577$, Prob. $=0.000<0.05$ ]. The null hypothesis of the study was rejected since there was a significant positive relationship between plan to budget and cash management. The study recommends that same study to be done in other remaining county governments. This study informed the executive management of Uasin Gishu County Government on how to improve management of cash by using IFMIS.
\end{abstract}

Keywords: Misappropriation, Efficient, Cash management, Integrated Financial Management.

DOI: $10.7176 /$ RJFA/10-18-12

Publication date:September $30^{\text {th }} 2019$

\section{Introduction}

Governments of developing countries have frequently explored techniques and systems on how to modernize and improve Cash Management in public sectors. Efficient running of public funds mainly focuses on budgeting, procurement and reporting. According to Zimmerer (2008) cash management is the process of predicting, gathering, distributing, investing and planning for finance a company requires in order to function efficiently. $\mathrm{He}$ went on to state that controlling of cash is a vivacious task due to the fact that cash is the most vital yet least productive asset owned by small business. For a business to be safe from being declared bankrupt, it must have sufficient cash to meet its obligations. Cash is the essential means of exchange and debtors, creditors and employees expect to be paid on time (Zimmerer, 2008).

In the Slovak Republic and Kosovo, IFMIS has been a fruitfully implemented in managing of public funds. Among them, Slovak is the only country with a well-organized IFMIS and is close to the commercial model. The IFMIS database in Caribbean and Latin America region of the World Bank has the largest number of active (4) and completed (25) IFMIS projects (World Bank, 2011). In Vietnam there has been progress of introducing a new IFMIS since 2001 funded by the World Bank. The new IFMIS system plans to cover the central administration as well as the 64 provincial administrations in Vietnam. The Iraqi government has a unique combination of cash and accrual accounting methods that is not easily compatible into the IFMIS system (USAID, 2008).

In Africa, there are thirteen completed and twelve active IFMIS projects. For all countries, the use of Information Communication Technology (ICT) for government reinvention is increasing not only in investment but also in terms of visibility with a number of high-profile initiatives having been launched during the 1990s (Muigai, 2012). In South Africa, IFMIS builds wider part of the financial management reforms of the South African government since 1994 when democracy was instituted. The enhancement of integrity, effectiveness of expenditure management and performance reporting which ensured effective service delivery was one of the objectives of IFMIS (Nomvalo, 2008). 
In Ghana, Aminatu (2015) looked at the impact of IFMIS on Ghana's economic development by looking at gross domestic product (GDP), economic growth, and resource allocation to major sectors of the economy. She noted from the analysis that some sectors of the economy contribute immensely to GDP growth whereas other sectors have an adverse effect. In Malawi, the country's financial accountability report indicates good institutional frame compared to most developing countries as a result of successful implementation of IFMIS (Aminatu, 2015). According to Rakner, Mukubve, Ngwira \& Smiddy, 2004, process of including a sound system was spearheaded by wise legislations that regulated finances, audits, and procurements which were in time for the Malawi budget. Our neighboring country, Uganda is among the countries that has successfully implemented IFMIS system. It was started in 2002 and was jointly financed by World Bank and Uganda government.

The development of IFMIS in Kenya started in 1998 but application in government ministries and departments started in 2003 (Kinyua, 2003). In county governments it started in the year 2013. The Government of Kenya has undertaken several cash management changes for over the last ten years which are aimed at improving accountability and transparency in management of public resources (GOK, 2011). These reforms aimed at core cash management systems of budget formulation and execution, public procurement process, internal and external audit activities, public debt, accounting and reporting. Major reform that was given priority is the automation of government expenditure processes. There was an assumption that the introduction of the Integrated Financial Management Information System (IFMS) in Kenya can effectively leverage on existing and emerging technology to enhance the pace of cash management changes (GOK, 2011). The system, initially ran on an Oracle Financial platform which was good for the system though it later developed some design issues hence required reengineering in 2011 (The National Treasury, 2013).

\subsection{Statement of the Problem}

This study emanates from the need for improved management of public cash allocated to county governments by Commission on Revenue Allocation (CRA) for sustainability of county governments and increased socioeconomic by county government management. The CRA allocated Ksh.329.34 billion to counties in equitable share and conditional grants for financial year 2017-2018 (Commission on Revenue Allocation, 2017). The Auditor General's Report, (2015) revealed that county governments have repeatedly been faced with misappropriation of public funds and lack of proper control systems to manage their cash effectively which has led to poor service provision and overspending.

Despite the employment of IFMIS as the main accounting system in counties since inception, lack of accountability in county government expenditures has been a concern to the whole public and international institutions eg IMF and World Bank (Auditor General's Report, 2015). There was a broad consensus that introduction of freely functioning IFMIS in Kenya will improve accountability of public funds by providing real time financial information useful to finance and other managers to dispense programs effectively, formulate budget and manage resources (GOK 2013).

Many studies have been done on the subject of public finance management. For instance, a study on evaluating financial management practices in the department of correctional services in South Africa by Mathiba (2011). In Ghana, Aminatu (2015) looked at the impact of IFMIS on Ghana's economic development by looking at gross domestic product (GDP), economic growth, and resource allocation to major sectors of the economy. In her analysis she noted that some sectors of the economy contribute immensely to GDP growth whereas other sectors have an adverse effect. Locally, Kiilu \& Ngugi (2014) did a study on effect of Public Financial Management Reforms in the Effective Management of Public Funds in Kenya. They found out that budgeting reforms have an effect on efficient management of public funds in Kenya National Treasury. Njonde \& Kimanzi (2014) did a study on impact of integrated financial management information system(IFMIS) on performance of public sector focusing on Nairobi County Government.

However, there lacks an empirical study done to assess the impact of IFMIS on cash management in Uasin Gishu County Government despite the county being among counties that get a large share of equitable revenue shared by counties (Controller of Budget, 2016). In the financial year 2017-2018, CRA allocated Uasin Gishu County Government Kshs.5,707,800,000 as equitable share of revenue raised nationally. The lowest allocation during that financial year 2017-2018 was for Lamu County Government Kshs.2,476,400,000 (CRA,2017). Hence, this research endeavored to establish the effect of IFMIS on cash management in the County Government of Uasin Gishu County Government.

\subsection{Objectives of the study}

(i) To establish the effect of plan to budget on cash management in Uasin Gishu County Government.

(ii) To find out the moderating effect of government policy on the relationship between IFMIS and cash management in Uasin Gishu County Government. 


\subsection{Research Hypothesis}

$\mathrm{H}_{0} 1$ : There is no significant effect between plan to budget and cash management in Uasin Gishu County Government.

$\mathrm{H}_{0} 2$ : There is no significant moderating influence of government policy on the relationship between IFMIS and Cash Management in Uasin Gishu County Government.

\subsection{Literature Review}

\subsection{Systems Theory}

This theory was the anchoring theory for this research on the effect of IFMIS on cash management in Uasin Gishu county government. Systems theory discusses information in the sense that assuming information does not necessarily involve any conscious mind, and patterns circulating (due to feedback) in the system can be called information (Wang, 2005). This means it can be stated that information in this sense is something hypothetically perceived as representation, though not created or presented for that purpose.

Rising Information and Communication Technology (ICT) promote greater transparency and comprehensiveness of information across government institutions. This can be vital in reducing corruption in public finance systems. Therefore, the introduction of IFMIS in public sector has been seen as an important component of public financial changes/reforms in many developing countries. This theory was used to anchor the study on IFMIS as a system and as a general theory of the study.

\subsection{Conceptual Framework}

A conceptual framework is product of qualitative processes of theorization or a plane of interlinked concepts that together provide a comprehensive understanding of a phenomena (Jabareen,2009). The conceptual framework developed for this study was drawn from system theory. Figure 2.1 represents conceptual framework showing systematic interpretation explaining the relationship between independent variables and dependent variable.

\section{Independent variables Dependent variable}

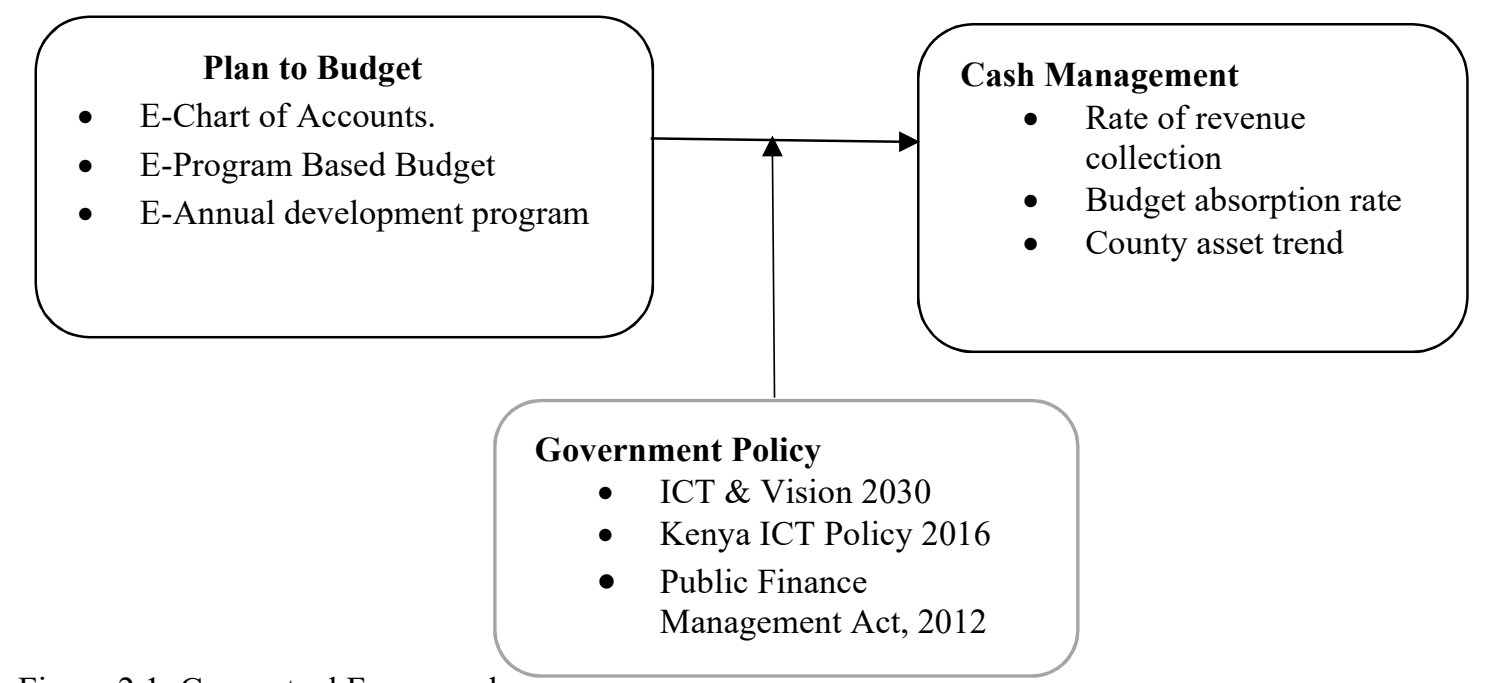

Figure 2.1: Conceptual Framework

Source: Author, 2019

The conceptual framework in Figure 2.1 shows IFMIS as independent variable, while Cash Management as dependent variable. Variable of IFMIS plan to budget as independent variable. Plan to budget was conceptualized by chart of accounts, Program Based Budget and annual development program. IFMIS is a standard system that monitors and reports, also sums up all the financial data requirements of a government into a single information database. Cash management was measured by rate of revenue collection, county asset trend and Budget absorption rate. The moderating variable was Government Policy and was measured by ICT \& Vision 2030, Kenya ICT Policy 2016 and Public Finance Management Act, 2012.

\subsection{Plan to Budget (P2B)}

Is a module of IFMIS that provides an integrated framework for development and deployment of a fully functional, automated planning and budgeting system, with aim of improving accuracy and efficiency in the government's planning and budgeting process. According to GoK, 2013 sources, P2B module has been fully implemented in all ministries and departments of national governments and agencies and the forty-seven (47) Counties.

Plan to budget is a fully structured process and system that connects planning policy objectives and budget allocation. Introducing an IFMIS necessitates unifying the codes and classifications (both the budget classification 
and the chart of accounts). According to Woods (2002), government budgets are important domain of public action by which policy objectives are chosen and acted upon and the necessary resources collected, allocated and spent. The systems of budgeting in the Government are also vital to donor agencies. Donors have a role of providing fiduciary safeguards and ensuring that foreign assistance funds remitted as direct budget support are properly used for their intended purpose. Pauw, Woods, Van der Linde, Fourie and Visser (2002) did a study on the role of budgeting on performance of organizations in United Kingdom. They found out that strong budgeting systems contribute to better overall standards of public sector governance.

\subsection{Government Policy}

IFMIS development and implementation in developing countries is determined by several factors. Though in Kenya, the national government has come up with ambitious steps in accepting and implementing IFMIS since 2003 in all ministries and departments, the County Governments are yet to fully adopt the same. IFMIS was introduced in county governments in 2013. For IFMIS project to be successful there ought to be ensured that there is a conducive legal and legislative environment with right government policies and regulations for system's development and implementation.

According to Obaji and Olugu (2014), entrepreneurial ventures by organizations are determined by government policies that include the use of modern technologies. They also added that government policies are great determinants of general entrepreneurial success in a nation. They also underscored the purpose of government policies towards acceptance and use of modern technologies. A study by Obaji and Olugu, 2014, found out that China has been experiencing fast growth of high technology businesses through appropriate government policies enacted by its Government. The achievements of Brazilian entrepreneurship movement as shown by the rising high technology oriented organizations has been due to development of technology oriented policies by the Brazilian government.

\subsection{Cash Management}

Cash management means the management of daily cash inflows and outflows in order to meet the day- to-day committals of an organization. Zimmerer (2008) describes cash management as the process of forecasting, collecting, disbursing, investing, and planning for cash a company requires to have seamless operations. Cash Management in government is misunderstood to be same us budget execution, accounting control or debt management; instead it is an exercise that focus on minimizing costs and managing government cash and their risks.

\subsection{Empirical Literature Review}

\subsubsection{Plan to Budget and Cash Management}

Pauw, Woods, Van der Linde, Fourie and Visser (2002) did a study on the role of budgeting on performance of organizations in United Kingdom. They found out that strong budgeting systems contribute to better overall standards of public sector governance. According to Dorotinsky (2003) there are several means in which IFMIS can increase public cash management, but the general way is that IFMIS enable confidentiality and credibility of the budget is through greater intensive and transparency of information. IFMIS improved budget planning and execution through provision of real time and accurate data for budget management and making decision. A more standard and true budget formulation across county governments is done by IFMIS, and further it promotes excellent command of budget execution through the full consolidation of budget execution data. It also allows decentralization of financial tasks and procedures under the overall control of the Ministry of Treasury. Further, it promotes financial prudence and control operational costs by minimizing administrative tasks and civil servants' workload.

\subsection{Research Gap}

While abundant literature exists on the subject of IFMIS, most of the studies have however not exhaustively investigated the relationship between IFMIS modules and cash management hence there were recommendations for further studies. The current study has filled the literature gap by establishing the link between IFMIS plan to budget module and cash management in Uasin Gishu County Government as a devolved unit in Kenya.

\subsection{Research Methodology 3.1 Research Design}

According to Yin, 2003, a research design is the legitimate sequence that links the empirical data to a study's hypothesis and, finally to its conclusions. The study adopted a descriptive survey research design a method that explores the relationship between the different variables in the study. It involved collecting information by administering a questionnaire to a sample of individuals (Orodho, 2005). Design is useful in identifying characteristics of an observed phenomenon or exploring possible correlations among two or more phenomena 
(Leedy, 2001). The research design enabled the researcher to integrate questionnaires, a pilot study and the actual survey as main procedures for data collection.

\subsection{Target Population}

Target population is the sum of components on which the researcher wishes to make some inferences (Ghauri \& Gronhaug, 2005). Also according to Mugenda \& Mugenda, 2009 target population can be outlined as an accomplished set of individuals, objects with some common observable features of a particular nature different from other population. The target population of this study consisted of 185 employees of Uasin Gishu County government from sections using IFMIS that is budgeting, accounts, internal audit, procurement and revenue section.

The practical consideration that dictated the choice of this study area was that Uasin Gishu County is among the counties that get large budgetary allocation from the national treasury. According to County Allocations 2016/2017 financial year, Uasin Gishu county was allocated Ksh. 6,030,878,991 (GOK 2016). Table 3.1 gives a summary of target population.

Table 3.1: Target population distribution matrix

\begin{tabular}{ll} 
Sections & No. of Employees \\
\hline Budgeting and planning & 10 \\
Accounts & 20 \\
Internal Audit & 5 \\
Procurement & 15 \\
Revenue & 135 \\
\hline TOTAL & $\mathbf{1 8 5}$ \\
\hline
\end{tabular}

Source: Human Resource Department Uasin Gishu County Government (March, 2019).

\subsection{Sampling Procedure and Sample Size}

Kombo \& Orodho, 2006 defines sampling techniques as a process of where a number of individuals are selected from a population such that the selected group has elements representative of the characteristics found in the entire target population. Mugenda \& Mugenda (2009) assert that a sample is a small group obtained from the accessible population as a representative of the whole population. Stratified sampling method was employed since the population under the study was not homogenous as it included respondents from different sections of the county government who use IFMIS. Simple random sampling technique was then adopted to select respondents from each stratum. The formula that the study used to arrive at a sample size of 177 respondents was based on Yamane (1967) formula indicated below.

Where:

$$
n=\frac{\mathrm{N}}{1+\mathrm{e}^{2}(\mathrm{~N})}
$$

n represents desired sample size

$\mathbf{N}$ represents the Target population

e represents the standard error (0.05)

Substituting the values in our formula gives approximately 177 respondents (see table 3.2) therefore a sample size of 177 respondents was selected randomly from each strata. According to Sekaran (2003) a sample that is larger than 30 and less that 500 is appropriate for most researches.

Table 3.2: Sample size distribution matrix

\begin{tabular}{llcc} 
Sections & Targeted population & Desired size & Sample size \\
\hline Budgeting and planning & 10 & $\frac{10}{1+(0.05)^{2}(10)}$ & 10 \\
Accounts & 20 & $\frac{20}{1+(0.05)^{2}(20)}$ & 19 \\
Internal Audit & 5 & $\frac{5}{1+(0.05)^{2}(5)}$ & 14 \\
Procurement & 15 & $\frac{15}{1+(0.05)^{2}(15)}$ & 129 \\
Revenue & 135 & $\frac{135}{1+(0.05)^{2}(135)}$ & $\mathbf{1 7 7}$ \\
\hline TOTAL & $\mathbf{1 8 5}$ & & \\
\hline
\end{tabular}




\subsection{Findings of the Study}

\subsection{Regression Analysis}

The study adopted Simple Linear Regression model to establish the effect of plan to budget on cash management in Uasin Gishu County Government. The following null hypothesis was tested by this model;

$\mathrm{H}_{01}$ : Plan to Budget module of IFMIS has no significant influence on cash management in Uasin Gishu County Government.

Table 4.1: Simple linear regression between plan to budget and cash management in Uasin Gishu County Government.

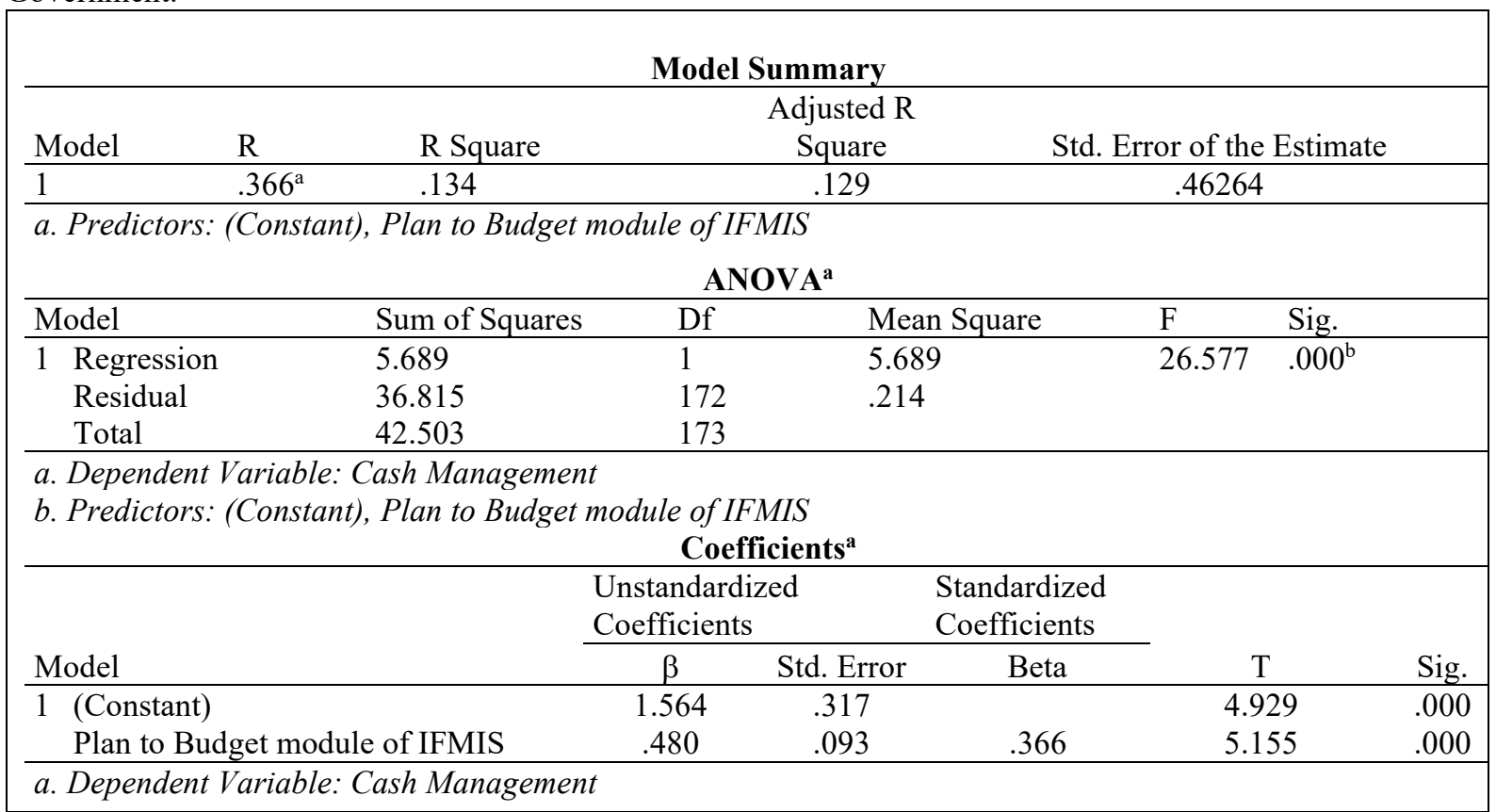

From the ANOVA results shown in table 4.1, it is evident that the Simple Linear Regression model well fitted in the dataset $[\mathrm{F}(1,172)=26.577, \mathrm{P}=0.000<0.05]$. Note that the model (Plan to Budget) explained $12.9 \%$ of the variation in cash management in Uasin Gishu County Government (Adjusted $\mathrm{R}^{2}=0.129$ ). The results of coefficients from Table 4.1 show that Plan to Budget had a statistically significant contribution in the prediction of cash management in Uasin Gishu County Government, $(\beta=0.480, t=5.155, p=0.000<0.05)$; thus the null hypothesis was rejected and concluded that Plan to Budget had a significant influence on cash management in Uasin Gishu County Government. Plan to Budget had a positive standardized beta coefficient $=0.366$ in the coefficients results of table 4.1; an indication that a Unit change in the Plan to Budget is likely to result to an improvement in cash management in Uasin Gishu County Government by 36.6\%. The Simple Linear Regression model to predict cash management in Uasin Gishu County Government using Plan to Budget was as follows: Cash Management $=1.564+0.480$ Plan to Budget module of IFMIS

The findings above agree with the previous works of Amos (2015) who studied the relationship between planning and budgeting in the public sector and found that good budgeting framework is built on an effective planning framework and that a plan ought to be linked with the budget to ensure effective implementation.

\subsection{Moderation effect of Government Policy on the relationship between Plan to Budget and Cash Management in Uasin Gishu county government}

The study also sought to establish the moderation effect of Government Policy on the relationship between IFMIS and Cash Management in the county government of Uasin Gishu. The Hierarchical Linear Regression model sought to test null hypothesis that follows; To find out the moderating effect of government policy on the relationship between IFMIS and cash management in Uasin Gishu County Government. The findings were captured in table 4.2. 
Table 4.2. Moderation analysis using Hierarchical Linear Regression analysis

\begin{tabular}{lccc}
\hline & \multicolumn{3}{c}{ Plan to budget(PB) module } \\
\cline { 2 - 3 } & Constant & PB & $\mathrm{I}_{\mathrm{PB}}$ \\
\hline Unstandardized $\beta$ & 2.070 & 0.078 & 0.075 \\
Standardized Beta & & 0.059 & 0.423 \\
Std. Error $(\beta)$ & 0.324 & 0.129 & 0.017 \\
$\mathrm{t}(\beta)$ & 6.386 & 0.603 & 4.316 \\
Sig. $(\beta)$ & 0.000 & 0.547 & 0.000 \\
$\mathrm{R}^{2}$ & 0.219 & & \\
Adjusted R $^{2}$ & 0.210 & \\
$\mathrm{R}^{2}$-Change & 0.085 & & \\
F $(1,171)$ & 23.966 & & \\
F-Change & 18.631 & & \\
Sig. (F-Change) & 0.000 & & \\
\hline Wh & & & \\
\hline
\end{tabular}

Where $\mathrm{I}_{\mathrm{PB}}=$ Interaction between government policy and Plan to Budget

In table 4.2 the interaction term between Plan to Budget and the Moderator variable (Government Policy) was added to the regression model between Plan to Budget and Cash Management through Hierarchical Linear Regression analysis. The Interaction effect $\left(\mathrm{I}_{\mathrm{PB}}\right)$ accounted for a significant proportion of the variance in Cash Management in Uasin Gishu County government as indicated in table 4.2 results, $R^{2}$ change $=0.085$, F-change $=18.631, \beta=0.075, t(174)=4.316, p=0.000<0.05$ : indicating that there was a potentially significant moderation effect by Government Policy on the relationship between Plan to Budget and Cash Management in Uasin Gishu County government. The moderated regression model was therefore given as follows.

$\mathbf{C M}=\mathbf{2 . 0 7 0}+\mathbf{0 . 0 7 8 P B}+\mathbf{0 . 0 7 5 I} I_{P B}$ Where;

$\mathrm{CM}=$ Cash Management

$\mathrm{PB}=$ Plan to Budget

$\mathrm{I}_{\mathrm{PB}}=$ Interaction between government policy and Plan to Budget

To examine the moderation effect of Government Policy on the relationship between Plan to Budget and Cash Management in Uasin Gishu County government, an interaction plot was plotted as shown in figure 4.3.

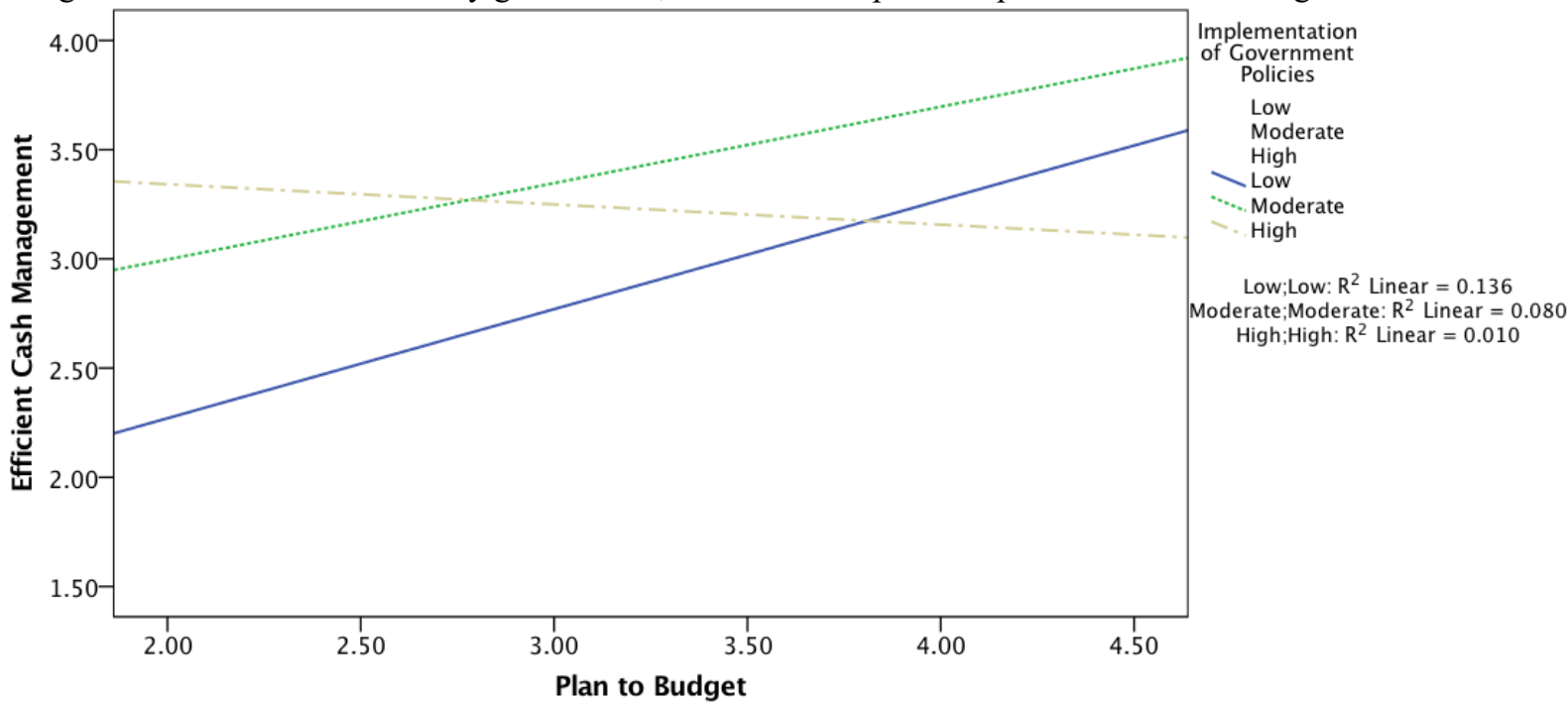

Figure 4.3: Interaction plot of Government Policies and Plan to Budget

Interaction plot of Government Policies and Plan to Budget as shown in figure 4.1 indicate that at Low and Moderate levels of enforcing Government policies, Plan to Budget module of IFMIS seem to have a relationship with Cash Management in the positive direction, such that Improvement in Plan to Budget module of IFMIS has a potential to lead to an increase in the Cash Management, but the influence seem to be high at Low level of enforcing Government policies compared to Moderate levels of policy enforcement as indicated by $\mathrm{R}^{2}=0.136$ and $\mathrm{R}^{2}=0.080$ respectively. When Government policies are highly enforced (at High levels), Plan to Budget module of IFMIS seem to have a relationship with Cash Management in the negative direction, such that Improvement in Plan to Budget module of IFMIS is likely to lead to decrease in the Government policies in Uasin Gishu County government and the influence seem to be the least compared to Low and Moderate levels of Government policies enforcement as indicated by $\mathrm{R}^{2}=0.010$ as shown in figure 4.10 above. 


\section{Conclusion}

In the first objective, the null hypothesis was rejected as there existed a statistically significant positive relationship between plan to budget and cash management. Majority of respondents revealed Plan to budget has improved seamless flow of information between planning section and budgeting section in Uasin Gishu County Government.

In the second objective of the study, the null hypothesis was rejected as government policy had a significant moderating influence on the relationship between IFMIS and cash management in Uasin Gishu County Government. Most of the respondents revealed that the Government has goodwill towards implementation of ICT processes in its operations.

\section{Recommendations}

Based on this study findings, it is suggested that for effective management of cash in the county government of Uasin Gishu through IFMIS;

(i) County development plans should be linked to county annual budgets for enhanced absorption of funds and implementation of projects.

(ii) An analysis of the achievements, challenges and lessons learnt from IFMIS should be conducted and held annually to identify gaps and improve efficiency and effectiveness.

\section{References}

Ajayi \& Omirin, (2007). Public Finance Management (PFM) system as a catalyst for economic. Growth and development. An Introduction. Nairobi Kenya: Paul Publications Africa.

Barrett, P., (2000). Balancing accountability and efficiency in a more competitive public sector environment, Australian Journal of Public Administration, Vol. 59 No.3, pp.58-71.

Gakuu and Ng'ang'a (2014). Factors influencing implementation of IFMIS in Kenya government ministries. Ministry of Finance, Meru County. The Financial Management of Public Sector in Kenya. Unpublished MBA Thesis, University of Nairobi.

Harash, E., Al-Tamimi, K. \& Al-Timimi, S. (2014). The relationship between government policy and financial Performance: A study on the SMEs in Iraq. China-USA Business Review, 13(4), 290-295.

Kothari, C.R. (2010). Research methodology: Methods and Techniques. New Age International (P) Ltd, New Delhi.

Miheso N. (2013). A review of IFMIS Reengineering Strategic Plan 2011-2013.Nairobi: Journal on IFMIS Reengineering August 2012.

Public Finance Management Act (2012). The Public Finance Management Act of 2012.

White (2005). Measurement: Reliability and validity measures. Johns Hopkins University. World Bank (2012). Public Financial Management.

Zimmerer, T.W., Scarborough, N.M., \& Wilson, D. 2008. Essentials of entrepreneurship and small business management. 5th ed. Upper Saddle River, New Jersy: Pearson/Prentice Hall. 